\title{
The bioluminescent field of the Atlantic Ocean
}

\author{
S. A. Piontkovski ${ }^{1}$, Yu. N. Tokarev ${ }^{1}$, E. P. Bitukov ${ }^{1}$, R. Williams ${ }^{2, *}$, D. A. Kiefer ${ }^{3}$ \\ ${ }^{1}$ Institute of Biology of the Southern Seas, 335011 Sevastopol, Ukraine \\ ${ }^{2}$ Plymouth Marine Laboratory, Prospect Place, Plymouth PL1 3DH, United Kingdom \\ ${ }^{3}$ Department of Biological Sciences, University of Southern California, Los Angeles, California 90089-0371, USA
}

\begin{abstract}
Data from 20 yr (1970 to 1990) of expeditions by the Institute of Biology of the Southern Seas, Ukraine, to the tropical Atlantic Ocean are summarised in the form of a macroscale contour map. The bioluminescent intensity of plankton in the upper $100 \mathrm{~m}$ layer was analysed from 2924 casts. Several zones of enhanced bioluminescence are shown from the annual averages $(0$ to $100 \mathrm{~m})$, associated with major upwellings along the African coast and geostrophic currents forming the westward water mass transport. The macroscale trend of spatial distribution and the stochastic component of the bioluminescence were partitioned by analysis of the autocorrelation functions. General agreement between bioluminescence and zooplankton biomass distributions was noted on an ocean basin scale. The contribution of phyto-and zooplankton fractions to the formation of the integrated bioluminescence potential can vary significantly in the upper $100 \mathrm{~m}$ layer over regions within the tropical zone.
\end{abstract}

KEY WORDS: Plankton bioluminescence Spatial heterogeneity Atlantic Ocean

\section{INTRODUCTION}

The integrative structural and functional biological characteristics of the oceanic biota, like the phyto- and zooplankton biomass, chlorophyll a concentration and primary production, are widely used in multipurpose studies of marine ecosystems. The numerous longterm measurements of these characteristics in various geographical regions have enabled macroscale generalisations to be made and maps of planktonic fields of the world ocean to be created (Bogorov et al. 1968, Koblentz-Mishke 1977, Semina 1977). Such maps have been progressively revised during recent decades for a number of regions (Chromov 1986, Piontkovski \& Ignatyev 1992, Rudjakov \& Tseitlin in pressj. Together with data on hydro-optical characteristics and water mass dynamics, such generalised observations serve as the basis for biogeographical partitioning of the oceans (McGowan 1971, Van der Spoel \& Heyman 1985, Longhurst et al. 1995).

\footnotetext{
- Addressee for correspondence.

E-mail: bw@wpo.nerc.ac.uk
}

The bioluminescence intensity or potential, measured for the whole community, can also act as an indicator of plankton abundance, biomass and functional state of planktonic ecosystems (Marra \& Hartwig 1984, Losee et al. 1989, Marra 1989, Evstigneev \& Bitukov 1990, Lapota et al. 1994). The plankton bioluminescence, however, is among those integrative characteristics which have never been amalgamated or represented in a form of the map, based on direct field measurements, for any large-scale region or the ocean. There are a number of reasons for this situation. Firstly, the majority of ongoing studies of bioluminescence in the sea were, and still are, located in the coastal zones. Secondly, it was mainly the former Soviet Union whose projects were associated with the long-term surveys of the open waters of the world ocean (1970 to 1990). However, these data were restricted in their publication and were generally inaccessible. The international cooperation programmes of data exchange between the former Soviet Union, Europe and the USA (IOC 1992) have enabled data to be amalgamated and jointly analysed.

We present the map of the Atlantic Ocean bioluminescence field for the first time. 


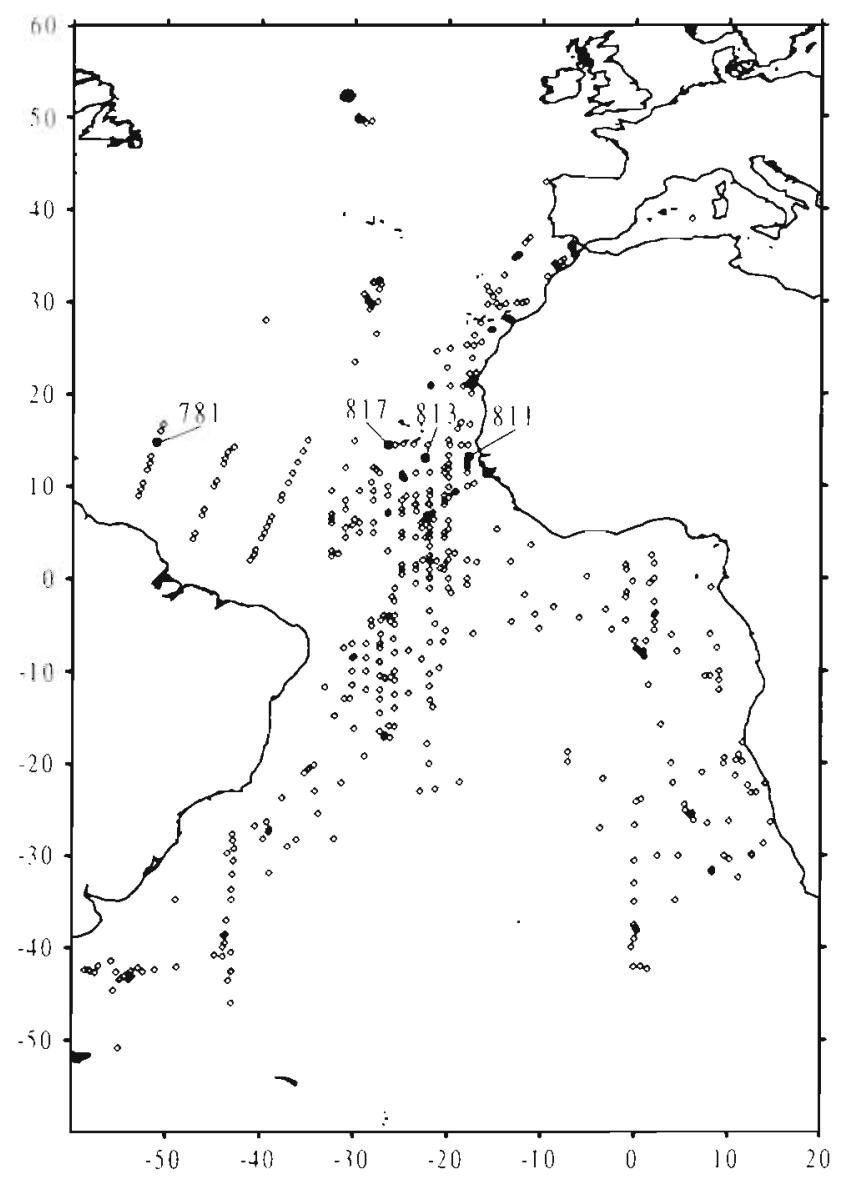

Fig. 1. Position of stations with vertical casts for bioluminescence and the 4 stations given in Table 2

\section{METHODS}

The bioluminescence potential or bioluminescence intensity was the major parameter in the long-term field measurements in the ocean. This potential is the maximum amount of radiant energy emitted in a given volume of water by stimulated bioluminescent organisms. This can be estimated as $B_{\mathrm{p}}=f B(t) \mathrm{d} t$, where $B(t)$ is the light intensity during the bioluminescent flash $(\Delta t)$.

Data were obtained from 15 expeditions of the Ukrain ian Academy of Sciences to the Atlantic Ocean (Fig 1, Table 1). Field surveys consisted of drift stations with measurements of bioluminescence potential down to $200 \mathrm{~m}$ depth, temperature, salinity, density profiles to $1000 \mathrm{~m}$ depth, and vertical hauls by Juday plankton nets (36 and $82 \mathrm{~cm}$ mouth diameter, 142 to $220 \mu \mathrm{m}$ mesh) stratified or integrated over $100 \mathrm{~m}$ depth.

Field measurements of bioluminescence (2924 vertical casts conducted at 523 stations) were mainly conducted within a period from $2 \mathrm{~h}$ after sunset to $2 \mathrm{~h}$ before sunrise, to exclude the impact of the vertical migrations of the plankton and the light diel rhythm.
Submersible gear. The bioluminescence intensity was measured by means of the bathyphotometer 'SALPA' (Vasilenko et al. 1997) with a dynamic band of 57 decibars. The bioluminescence sensor was mounted at the bottom of a cylinder and detected the bioluminescence emitted by organisms within a dark chamber This dark chamber had a light protecting screen and 4 impellers rotating on a fluoroplastic bearing. The pitch of the impeller vanes protected the chamber from external light. When the instrument is lowered the impellers are rotated by the flow of water The rotating impeller vanes mechanically disturb the plankton organisms passing through the dark chamber, causing them to bioluminesce prior to measurement by the bioluminescence sensor. The electrical signal from the sensor is transmitted up a single cable, with temporal partitioning of the channels, to the deck unit. The sensitivity of the bioluminescence sensor is in a range from $10^{-13}$ to $10^{-8} \mathrm{~W} \mathrm{~cm}^{-2}$ with a band of spectral sensitivity from 160 to $600 \mathrm{~nm}$. The repeat time of the bioluminescence, temperature and conductivity sensors was $180 \mathrm{~ms}$. The bathyphotometer was deployed vertically at a speed of $1.3 \mathrm{~m} \mathrm{~s}^{-1}$. The bioluminescence of planktonic organisms has a total latent period and flash duration less than 0.6 s (Evstigneev \& Bitukov 1990) which means that the sensor can easily measure the bioluminescence signal. The bioluminescence signals coming from the submersible unit were recorded and averaged over $5 \mathrm{~s}$ intervals. To calibrate the bioluminescence sensor a radioactive-luminescent light source was used. The light intensity of this standard source was $1.2 \times$ $10^{-8} \mathrm{~W}$. A measure of the background light was taken as the minimal bioluminescence signal from $1 \mathrm{~m}$ depth. The depth of the submersible gear was estimated by means of the pressure sensor DDV (precision 0.01 MPa).

Table 1 General characteristics of data used for the mapping of bioluminescence

\begin{tabular}{|lccc|}
\hline Year & Month & $\begin{array}{c}\text { Number } \\
\text { of stations }\end{array}$ & $\begin{array}{c}\text { Number } \\
\text { of profiles }\end{array}$ \\
\hline 1970 & Aug-Sep & 12 & 12 \\
1972 & Mar-Jun & 26 & 26 \\
$1972-73$ & Dec-Mar & 21 & 21 \\
1974 & Feb-Mar & 11 & 11 \\
$1973-74$ & Dec-Mar & 42 & 42 \\
1976 & Apr-Jul & 57 & 57 \\
$1976-77$ & Dec-Jan & 41 & 41 \\
1977 & Jul-Aug & 41 & 41 \\
$1978-79$ & Dec-Feb & 38 & 38 \\
1981 & Jan-Apr & 35 & 442 \\
$1981-82$ & Dec-Jan & 30 & 553 \\
1982 & Jul-Oct & 48 & 793 \\
$1985-86$ & Nov-Jan & 28 & 626 \\
1987 & Jun-Sep & 66 & 66 \\
1989 & Oct-Dec & 27 & 155 \\
\hline
\end{tabular}


The absolute errors of the other sensors were $0.01^{\circ} \mathrm{C}$ for temperature and $8 \times 10^{-4} \mathrm{~cm} \mathrm{~m}^{-1}$ for the conductivity channel. The integration time of the bioluminescence sensor was manually regulated in a band from 0.5 to $5 \mathrm{~s}$. An 'ISTOK' CTD (with a temperature sensitivity of $0.0025^{\circ} \mathrm{C}$, a measurements error of $0.001^{\circ} \mathrm{C}$, and a time lag for the sensor of about $50 \mathrm{~ms}$ ) was used for vertical profiling. The specific electrical conductivity was 1.3 to $7.0 \mathrm{~cm} \mathrm{~m}^{-1}$, the sensitivity was $0.0025 \mathrm{~cm} \mathrm{~m}^{-1}$ with a measurement error of $0.002 x$ (where $x$ is the conductivity number). The hydrostatic pressure was estimated by means of the pressure sensor with a band of 0 to $60 \mathrm{MPa}$ (0 to 6000 dbar), a sensitivity of 0.004 to $0.007 \mathrm{MPa}$ and a measurement error of $0.25 \%$.

Data processing. To map the bioluminescence potential of the upper $100 \mathrm{~m}$ layer the bioluminescence numbers in the vertical profiles were averaged. The Surfer ${ }^{(*)}$ Golden Software Inc. (USA) package was applied to design the macroscale field of the bioluminescence potential. The Kriging gridding method (Cressie 1991) and smoothing of the grid matrix, with the weight of matrix center $=2$ and the distance weighting power $=2$, were applied to create the bioluminescence map. Twodimensional spatial autocorrelation functions were used to estimate the statistical structure of the stochastic (subgrid) component of the bioluminescent field.

Phyto- and zooplankton fractions of plankton samples were treated to the level of species. The abundance of the bioluminescent, the probably bioluminescent and non-bioluminescent species of both fractions were defined on the basis of a bioluminescent species list summarised in a number of reviews (Clarke et al. 1962, Lapota \& Losee 1984, Evstigneev \& Bitukov 1990, Gitelzon et al. 1992, Evstigneev et al. 1993). The probably bioluminescent species are those species whose bioluminescence is still a subject of debate.

To estimate the degree of similarity in changes of the bioluminescence potential, principal component analysis was applied to the phyto- and zooplankton abundance. Parameter numbers were subjected to $\log (x+1)$ transformation. The rotated loadings and the percentage of variance explained by components were defined on the basis of the VARIMAX procedure. The Pearson correlation matrix and linear regression analy. sis were used to estimate statistical links between bioluminescence potential and above-defined $\log (x+1)$ transformed plankton components.

\section{RESULTS}

The selection of the $100 \mathrm{~m}$ layer for processing and averaging of vertical profiles was based on the preliminary analysis of the whole data set. This has shown that about $90 \%$ of the bioluminescence potential of the
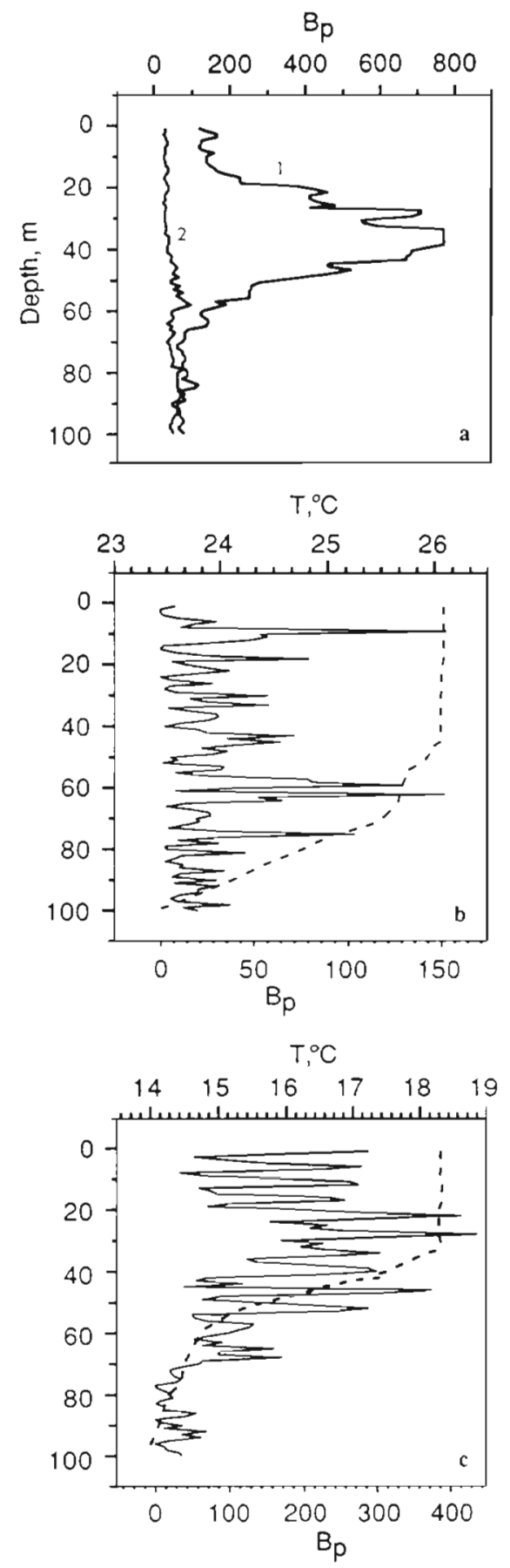

Fig. 2. Typical vertical profiles of bioluminescence intensity and temperature from various regions. (a) $1: 0^{\circ} 30^{\circ} \mathrm{S}, 1^{\circ} 30^{\prime} \mathrm{E}$ (March 1981); 2: $28^{\circ} 00^{\prime} \mathrm{N}, 39^{\circ} 29^{\circ} \mathrm{W}$ (September 1982); (b) $13^{\circ} 19^{\prime} \mathrm{N}, 51^{\circ} 43^{\prime} \mathrm{W}$ (February, 1974); (c) $14^{\circ} 30^{\prime} \mathrm{N}, 17^{\circ} 55^{\prime}$ W (March 1974). T: temperature (dashed lines); $\mathrm{B}_{\mathrm{p}}$ : bioluminescence intensity $\left(10^{-6} \mu \mathrm{W} \mathrm{cm}^{-2} \mathrm{I}^{-1}\right)$

epipelagia lies in the upper $100 \mathrm{~m}$ layer. Patterns of vertical profiles (the number of bioluminescent peaks, their amplitudes, their position by depth, etc.) might be distinctive for specific regions (Fig. 2). The compar- 


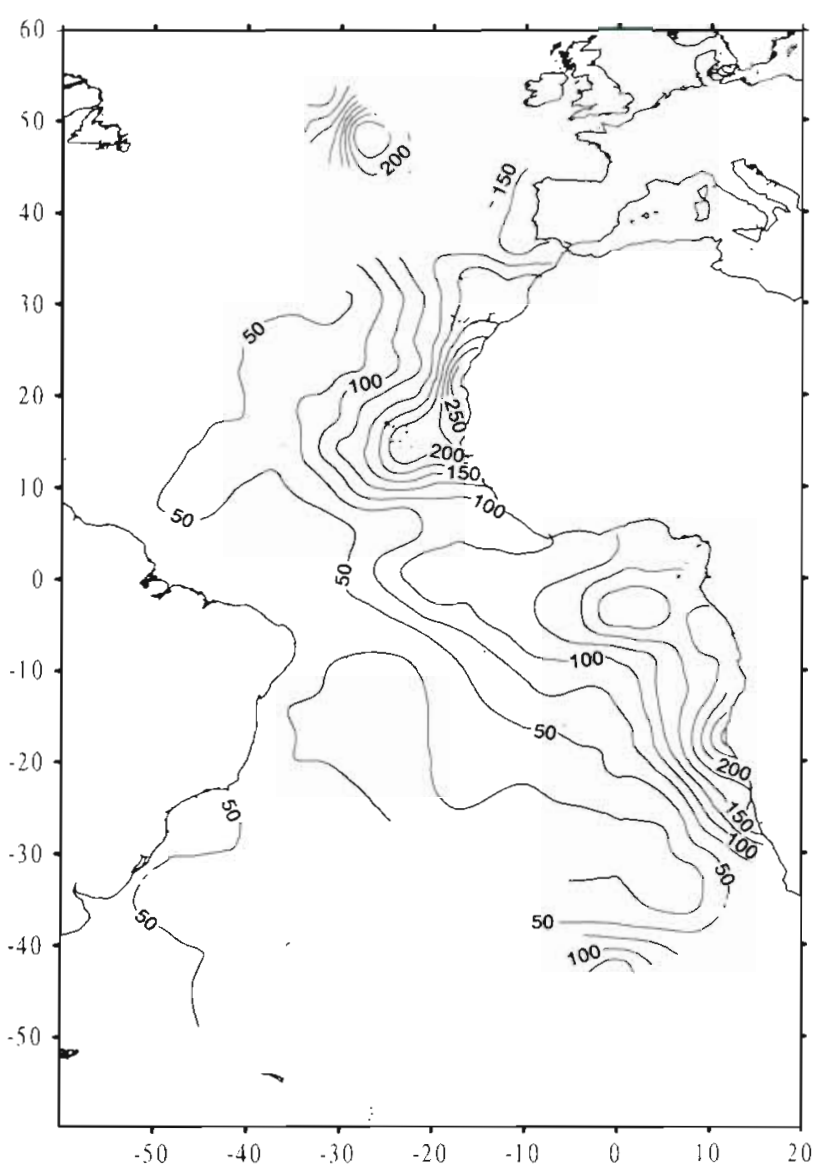

Fig. 3. Map of bioluminescence intensity $\left(10^{-5} \mu \mathrm{W} \mathrm{cm}^{-2} \mathrm{I}^{-1}\right)$ of the Atlantic Ocean (0 to $100 \mathrm{~m}$ )

isons of the profiles of bioluminescence intensity with those of phyto-and zooplankton allow us to conclude that the wide-bottom peaks of bioluminescence (Fig. 2a) were mainly formed by increased abundance of plankton organisms while the fine resolved peaks are due to single flashes from copepods or micro swarms. In some cases profiles have (1) 1 wide and well-defined maximum of bioluminescence usually associated with the thermocline layer, (2) profiles have several maxima or (3) the vertical profiles reflect the stratified biotope, where numerous layers of minimal and maximal bioluminescence are separated by several metres. Finally, vertical statification of bioluminescence might not be well developed and profiles might have 1 or 2 low-amplitude peaks separated by 20 to $30 \mathrm{~m}$ depth. The variety of vertical structure will certainly affect the macroscale mapping of the bioluminescence at any of the horizons within the euphotic layer but the maps we give integrate through all this variability. Analysis of the fine structure and diversity of the vertical profiles is not within the scope of this paper.

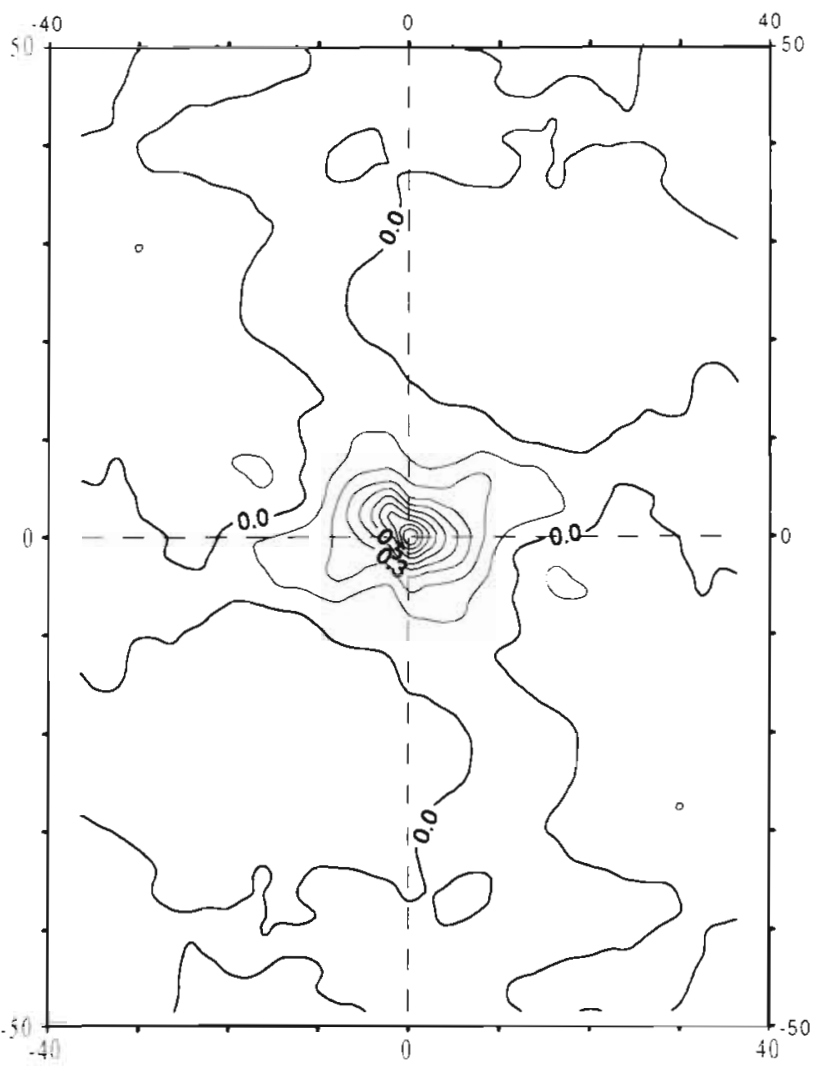

Fig. 4. Two-dimensional spatial autocor relation function of the stochastic (subgrid) component of the bioluminescent field

The bioluminescent field of the tropical and subtropical Atlantic Ocean exhibits some well developed and visually defined patterns. Firstly, there is a general trend of decreasing bioluminescence intensity from the eastern to the western regions, especially from the African upwelling regions towards South America. On average, bioluminescence decreases 5 times or more from 250 to $50-20 \times 10^{-5} \mu \mathrm{W} \mathrm{cm} \mathrm{cm}^{-2} \mathrm{l}^{-1}$ (Fig. 3).

The other feature is the less scaled variations against the background of this general macroscale trend. The well-developed zones of enhanced bioluminescence take the form of tongues streching west from the African upwelling zones towards the open ocean. The northern and central tongues cover regions of the Mauritanian coastal upwelling and the so-called Guinea Dome. In the latter case, a quasi-stationary cyclonic circulation takes place and could be monitored in a region with approximate coordinates $11^{\circ}$ to $13^{\circ} \mathrm{N}$, $21^{\circ}$ to $22^{\circ} \mathrm{W}$ (Artamonov et al. 1987) The 'southern tongue' is more elongated along the African shelf. I.t covers the Benguela upwelling region and the Angolan Dome, extends to the north and then curls westward near the equator. The central and western regions of the South Atlantic have low productive oligo- 
trophic waters where bioluminescence declines below $50 \times 10^{-5} \mu \mathrm{W} \mathrm{cm}^{-2} \mathrm{I}^{-1}$.

To evaluate the features of the stochastic component of the bioluminescent field, the macroscale spatial trend and the field of the subgrid stochastic fluctuations were separated and analysed on a statistical basis (Fig. 4). The 2-dimensional spatial autocorrelation function (ACF) of the pulsation or stochastic component (characterising the synoptic scale processes) exhibits spatial anisotropy. Obviously bioluminescence fluctuations are statistically linked on a space scale of about $5^{\circ}$ to $7^{\circ}$ along latitude and longitude. On the other hand, if we consider the so-called correlation radii of the ACF up to a 0.1 correlation value, zones of correlated fluctuations of bioluminescence obviously appear to be distributed along the equator and latitudinally in the direction of the main water mass transport. Spatial heterogeneity of the bioluminescent field is also related to such synoptic events as frontal zones and current meanders. For example, in the South Atlantic, contours of the $100 \mu \mathrm{W} \mathrm{cm}^{-2} \mathrm{l}^{-1}$ isoline relate to the westward curl and the position of the macroscale divergent zones (see schemes of currents in Martinenko 1990)

It is known that bioluminescence intensity can be associated with mesozooplankton biomass values in tropical waters. To compare trends on the macroscale we used data on zooplankton sampling summarised from 42 expeditions by former Soviet Union research vessels to the Atlantic Ocean (Fig. 5; see also Piontkovski \& Ignatyev 1992). The sampling statistics are given in Fig. 6 and show an excellent spread throughout the year. The zooplankton wet weight biomass map was created on the basis of integrated catches (0 to $100 \mathrm{~m}$ layer) conducted at 1346 stations from 1950 to 1989 . To produce a map comparable with that of bioluminescence, stations with night samples only were selected.

What is obvious from the simple visual comparison of both fields is that trends of bioluminescence, described above qualitatively, are similar to those of zooplankton biomass. However, the contribution of phyto- and zooplankton fractions to the formation of integrated bioluminescence potential can vary over the Atlantic Ocean regions. To illustrate this we analysed data from a number of stations (Stns 811, 813, 817 and 781) (Table 2, Fig. 1) where coincident samples were taken and processed in detail. These stations were distributed approximately within the same latitude, in the main water mass transport, from the northern African upwelled waters to the western oligotrophic regions. The differences between the productive (Stns 811 and 813) and oligotrophic regions (Stn 781) are shown in the seston abundance, which was 6 to 7 times greater, and bioluminescence, which was about 30 times greater (Table 2). What can also be observed is the decrease in abundance of bioluminescent Pyrrophyta algae and copepods from the eutrophic coastal waters off northwest Africa to the oligotrophic oceanic waters. However, it is difficult to determine from our data whether or not the relative contributions of phyto- and zooplankton to the bioluminescence intensity change in any systematic way in the same direction.

For the primary production, the differences were on the order of 1 magnitude for these regions (Kondratieva \& Markova 1975, Greze et al. 1984). To make the spatial resolution of bioluminescence and plankton sampling comparable over depths, all values of the variables were averaged within several layers $(0-10$, $10-25,25-50,50-75,75-100 \mathrm{~m})$. These averaged and 


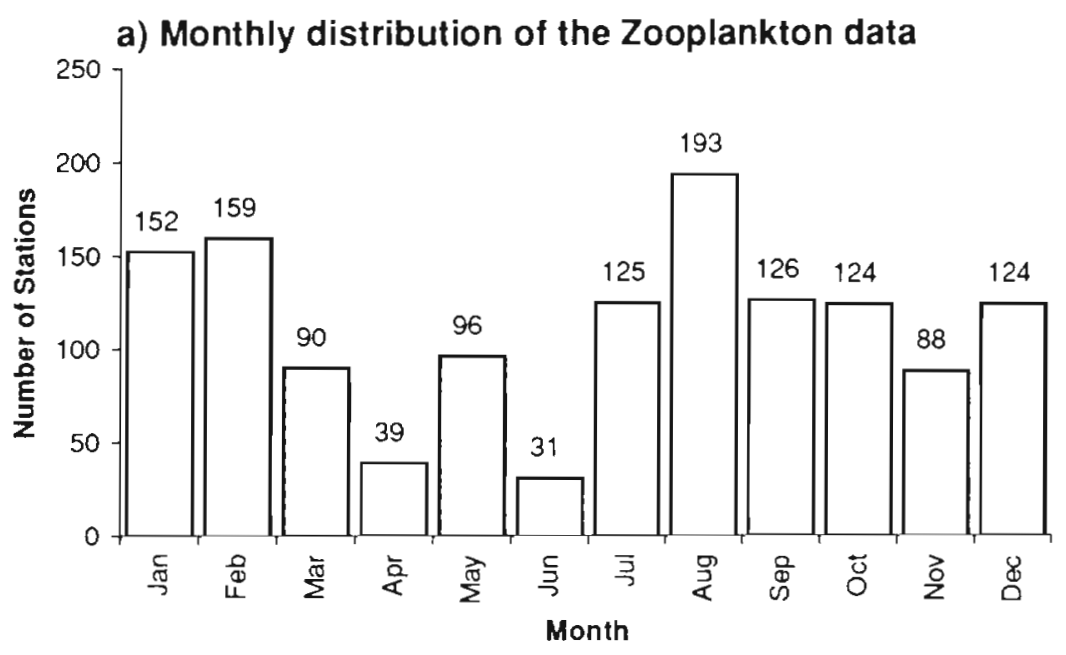

b) Year distribution of the Zooplankton data

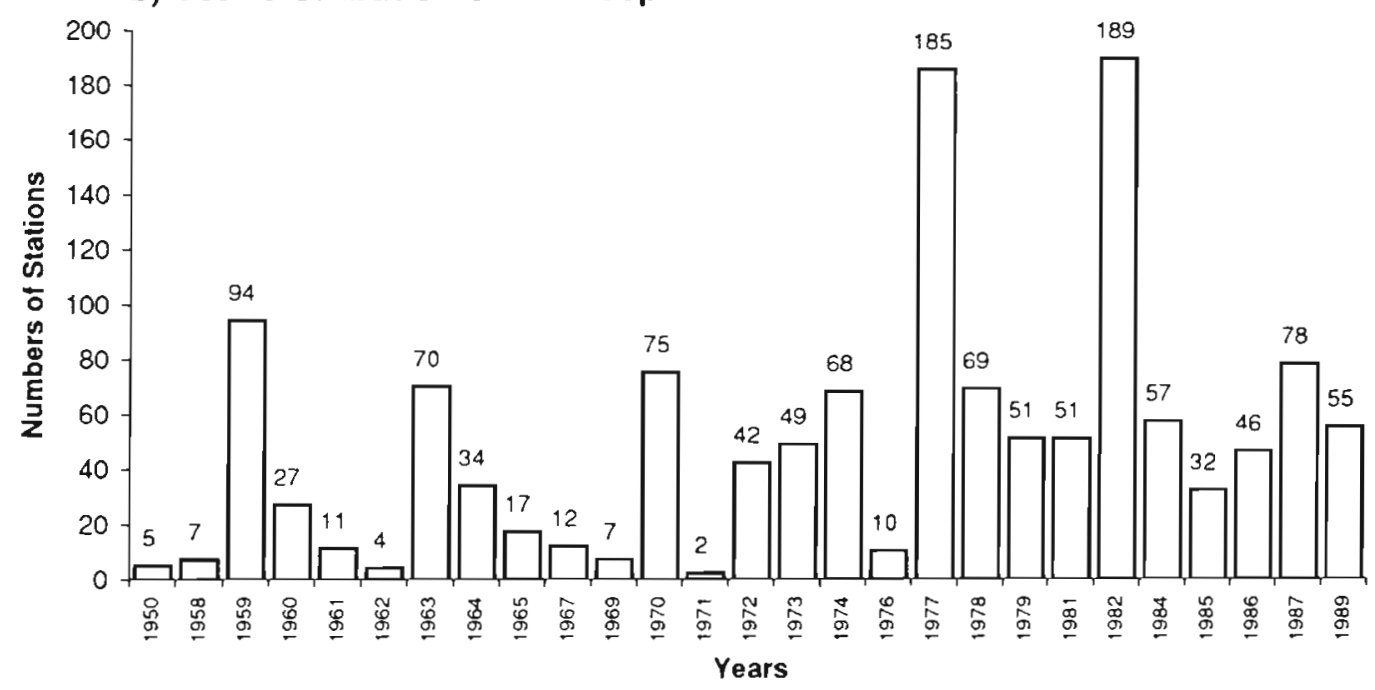

Fig. 6. Month and year distribution of the data in Fig. 5

spatially compatible data containing bioluminescence values and abundance of bioluminescent species of phyto- and zooplankton were subjected to principal component analysis and the Pearson correlation analysis. The first 2 principal components explained about $75 \%$ of the total variance for the given regions. The bioluminescence potential, seston biomass and abun- dance of bioluminescent copepods formed the main part of the first principal component in the highly productive waters, whereas the bioluminescent Pyrrophyta algae and the relatively bioluminescent copepod species formed the main contribution to the second principal component which explained $37 \%$ of the total varıance.

Table 2. Characteristics of the planktonic community $(0$ to $100 \mathrm{~m})$. Biolum. $\left(10^{-12} \mathrm{~W} \mathrm{~cm}^{-2}\right)$ : bioluminescence intensity; Seston (mg $\mathrm{m}^{-3}$ ): all plankton components collected by Juday net, $36 \mathrm{~cm}$ mouth diameter, 124 to $145 \mu \mathrm{m}$ meshi $\mathrm{Pyr}_{\text {iot }}\left(10^{3}\right.$ cells m $\left.{ }^{-3}\right)$ : total abundance of Pyrrophyta algae; Pyr $\left(10^{3}\right.$ cells $\left.\mathrm{m}^{-3}\right)$ : abundance of bioluminescent species of Pyrrophyta algae. Cop. 1 (ind $\mathrm{m}^{-3}$ ): abundance of bioluminescent species of copepods; Cop. 2 (ind $\mathrm{m}^{-3}$ ): abundance of relatively bioluminescent species

of copepods; Cop. $1+2$ (ind. $\mathrm{m}^{-3}$ ): sum of the definitively bioluminescent and relatively bioluminescent species of copepods

\begin{tabular}{|c|c|c|c|c|c|c|c|}
\hline Stn & Biolum. & Seston & Pyr $_{\text {tot. }}$ & Pyr $_{\text {lum }}$ & Cop. 1 & Cop. 2 & Cop. $1+2$ \\
\hline $811\left(14.5^{\circ} \mathrm{N}, 17.9^{\circ} \mathrm{W}\right)$ & 135 & 1890 & 13037 & 1391 & 116 & 827 & 944 \\
\hline $813\left(14.6^{\circ} \mathrm{N}, 23.7^{\circ} \mathrm{W}\right)$ & 886 & 1430 & 11440 & 1250 & 165 & 866 & 1032 \\
\hline $817\left(14.5^{\circ} \mathrm{N}, 26.4^{\circ} \mathrm{W}\right)$ & 29 & 460 & 20913 & 700 & 66 & 439 & 505 \\
\hline $781\left(13.3^{\circ} \mathrm{N}, 51.7^{\circ} \mathrm{W}\right)$ & 27 & 240 & 13957 & 375 & 76 & 175 & 251 \\
\hline
\end{tabular}


In the low productive area (Stn 781) the first 2 principal components explained approximately equal parts of the total variance ( 31 and $34 \%$ ). The relatively bioluminescent copepods and the bioluminescent potential itself form the main contribution to the first principal component, whereas the second one is formed mainly by the seston biomass.

\section{DISCUSSION}

The map in Fig 3 represents the seasonally averaged 2-dimensional field of the bioluminescence potential. This type of averaging smoothes the other patterns and components of spatial-temporal variability. However, our goal was to create, at this stage, the average map of bioluminescence, to compare with maps of primary production and phyto- and zooplankton (Bogorov et al. 1968, Koblentz-Mishke 1977, Semina 1977). In this respect we wanted to complete the mapping of general patterns of the biological structure of the Atlantic Ocean pelagia on a basin scale and to compare them later with data obtained from the deployment of 'SALPA' in the Mediterranean Basin (Bitukov et al. 1997) and with data obtained in the Pacific Ocean (Gitelzon et al. 1992).

The contribution of the phyto- and zooplankton fractions to the formation of the bioluminescence potential is controversial. The ratio and the role of components can be distinctly different over the Atlantic Ocean, even within the tropical latitudes. In the northwest tropical Atlantic (e.g. 3 macroscale transects of the Brazilian coast, $2^{\circ}$ to $17^{\circ} \mathrm{N}$; Fig. 1) the dominant superficial bioluminescents were algae of the genera Glenodinium, Peridinium and Exuviaella (Evstigneev et al. 1990). The contribution of phyto- and zooplankton fractions to the formation of the bioluminescence potential was not assessed by the authors.

In the upper $200 \mathrm{~m}$ of the Sargasso Sea the majority of the stimulated bioluminescence is produced by crustaceans, larvaceans and colonial radiolarians, and dinoflagellates produced 5 to $30 \%$ of the measured bioluminescence (Swift et al. 1983, 1985). A considerable role of zooplankton in the formation of the stimulated bioluminescence was noted for a number of other tropical regions, e.g. the Red Sea (Rudjakov \& Voronina 1967) and the whole tropical Pacific Ocean (Gitelzon et al. 1992). At the same time it was noted that for regions such as the Red Sea and the Gulf of Aden both fractions (i.e. phyto- and zooplankton) contribute to the variance of bioluminescence potential during the summer months (Rudjakov 1968).

The macroscale changes of bioluminescence intensity become understandable from a comparison with the system of currents acting in the tropical Atlantic
Ocean through the year in both hemispheres. In the northern tropical and subtropical latitudes the Canary Current passing along the northeastern African coast entrains the highly productive waters fed by intensive coastal upwelling (Herbland et al. 1983). The Canary Current forms and feeds, in turn, the limbs of the North Passat Current crossing the Atlantic approximately at latitudes $10^{\circ}$ to $13^{\circ} \mathrm{N}$ (Martinenko 1988, 1990). The Interpassat Counter-Current acts in the opposite direction, ensuring the easterly directed water mass transport. The interaction of the above currents and the longitudinally elongated equatorial divergence zone affects the formation of enhanced values of bioluminescence and zooplankton biomass and the zonally oriented position of their isolines. The macroscale system of currents in the upper layer also includes a vertical component, which forms as the consequence of the divergence of horizontal flows. The wind-driven surface divergence and the subsurface structure of water masses are closely coupled at the tropical Atlantic latitudes (Levitus 1982, 1988, McClain \& Firestone 1993). As a result of this coupling the coastal upwelling events, interacting with the Ekman transport, affect spatial patterns of planktonic fields on an ocean basin scale.

In the southern hemisphere the system of currents forms the anticyclonic gyre acting on a scale of the whole southern Atlantic Ocean (Greze et al. 1984). Currents propagating along the African continent, i.e. the Benguela Current, carry the upwelled productive waters. Currents acting along the east coast of South America, i.e. the Brazilian Current, are less productive. The central part of the South Atlantic Ocean more or less coincides with the position of the center of this anticyclonic gyre, where the most oligotrophic waters are observed. For instance, differences between the Benguela and Brazilian Currents amount to 5-10 times for the bioluminescence potential and phytoplankton biomass, 5 times for phosphorus concentration and 1.5 times for the averaged temperature in the upper $100 \mathrm{~m}$ layer (Greze et al. 1984).

Our observations from the tropical plankton community of the Atlantic Ocean (where the majority of our bioluminescence measurements were taken) are less subject to seasonal changes than at other latitudes (Greze et al. 1984). Thus, Oudot \& Morin (1987) found no considerable changes in the chlorophyll values within the euphotic zone $\left(5^{\circ} \mathrm{N}\right.$ to $\left.9^{\circ} \mathrm{S}, 4^{\circ} \mathrm{W}\right)$ in July and August compared to January and February in 1983. Primary production measurements, integrated over the euphotic zone, also exhibited no remarkable seasonal changes in the equatorial zone (Herbland et al. 1983). However, maps of chlorophyll a reconstructed from satellite data exhibit well-defined seasonality (Longhurst 1993). On the basis of $1979 / 80$ data 
it was shown that a major bloom starts in June, extends westwards (to $40^{\circ} \mathrm{W}$ ) by September and regresses in January.

Where plankton and bioluminescence measurements were conducted simultaneously (Table 2, Fig. 2) it seems that the variance of bioluminescence itself might be high both horizontally and vertically. These variations can be statistically linked with variations of abundance of phyto- and zooplankton. For example, the correlation value ( $r$ ) between bioluminescence potential and the abundance of bioluminescent species of copepods was 0.85 to 0.99 for Stns 811 and 813 from the highly productive waters. The correlation coefficient between bioluminescence potential and the abundance of bioluminescent species of Pyrrophyta algae was 0.78 for Stn 813 . Both plankton fractions play a statistically significant role in the formation of the contribution to the 2 principal components which explain about $75 \%$ of the total variance in these regions.

In the oligotrophic waters of the western regions the weak bioluminescence potential was not correlated with changes of Pyrrophyta algae and exhibited less developed correlation $(\mathrm{r}=0.6, \mathrm{p}=0.01$ ) with copepods also being abundant.

The longitudinal/latitudinal orientation and the elongation of spatial gradients were developed not only in the bioluminescence field of the tropical Atlantic but in the relationship between zooplankton biomass and temperature (Fig. 7 in Piontkovski \& Williams 1995). The statistical relationship of the variables of zooplankton and temperature in 2-dimensional space has the form of an ellipse, stretched along the longitude. The ratio of the longitudinal to latitudinal axis of this ellipse is close to $3: 1$ (Piontkovski \& Williams 1995). This ratio might serve as a measure of the spatial anisotropy of a parameter field. It was suggested that the given anisotropy of the relationship between the zooplankton and temperature is the consequence of the longitudinal orientation of currents and macroscale dymamic events (convergence and divergence zones) throughout the studied area.

In the case of the statistical structure of the bioluminescent field the stochastic component possibly points out the dual origin of spatially related fluctuations. Firstly, it is the impact of the easterly and westerly oriented currents, and secondly, it is the equatorially oriented physical processes. They overlap and lead to the 'cross form' of the 2-dimensional spatial autocorrelation function of the stochastic component of the bioluminescent field (Fig. 4). Spatially correlated fluctuations of bioluminescence were oriented along the main directions of water mass transport or macroscale equatorial divergences and were related on a scale of 600 to $800 \mathrm{~km}$.
Considering the ocean basin scale, then the evaluated bioluminescent field of the Atlantic Ocean is in sufficient concordance with the known patterns of distribution of zooplankton biomass. Further efforts are required to amalgamate data on zooplankton, phytoplankton, chlorophyll a and irradiance parameters on an ocean scale. These data, together with temperature profiles, would enable the bioluminescent field of the ocean to be derived. Algorithms relating the abovementioned parameters are being developed (Kiefer \& Ondercin 1993, Ondercin et al. 1996) and are the aims of our further studies. Such developments would enable the bioluminescent field of the ocean to be linked with remotely sensed physical fields on a global scale.

Acknowledgements. We thank B. Sokolov and V Vasilenko for their help in the database formation. Plankton samples were processed by $T$ Narusevich, L. Hlyistova and $A$. Ivanova. This work was a part of the international cooperation programme between IBSS, PML and USC and was partly funded by ONR grant No. N00014-95-1-0089.

\section{LITERATURE CITED}

Artamonov YuV, Polonsky AB, Pereyaslavsky M (1987) Investigations of the macroscale water circulation in the northeastern part of the tropical Atlantic. Deposited in VINITI Archives No. 391-B 87 Mar Hydrophys Inst, Sevastopol (in Russian)

Bitukov EP, Tokarev YuN, Piontkovski SA, Vasilenko VI Williams R, Sokolov BG (1997) The bioluminescent field as an indicator of the spatial structure of the planktonic community of the Mediterranean Sea Basin. In: Hastings JW, Kricka LJ, Stanley PE (eds) Bioluminescence and chemiluminescence. Molecular reporting with photons. John Wiley \& Sons, Chichester, p 169-171

Bogorov VG, Vinogradov $M E$, Voronina NM, Kanaeva IP, Syetova IA (1968) The distribution of zooplankton biomass in the upper layer of the world's ocean. Rep USSR Acad Sci (Dokladyi Academii Nauk SSSR) 182:232-245 (in Russian)

Chromov NS (1986) Some peculiarities of the plankton quantitative distribution in the Atlantic Ocean. In: Biological resources of the Atlantic Ocean (Biologicheskie resyrsy) Atlanticheskogo okeana). Nauka, Moscow, p 157-175 (in Russian)

Clarke GL, Conover RJ, David CN, Nicol JA (1962) Comparative studies of luminescence in copepods and other marine animals. Limnol Oceanogr 4:163-180

Cressie NAC (1991) Statistics for spatial data. John Wiley \& Sons, New York

Evstigneev PV, Bitukov EP (1990) Bioluminescence of marine copepods (Bioluminescenciya morskih copepod). Naukova Dumka, Kiev (in Russian)

Evstigneev PV, Bitukov EP, Okolodkov JE (1993) Species composition and specificity of bioluminescence of Dinophyceae algae. Bot Zh 78:1-15 (in Russian)

Evstigneev PV, Voronova OK, Scherbatenko PV, Bocharova RK (1990) A study of bioluminescence of the superficial layer of the tropical Atlantic Ocean. Ekolo Mor 34:15-21 (in Russian)

Gitelzon II, Levin. LA, Utyshev RN, Cherepanov OA, Chugunov 
YuV (1992) Ocean bioluminescence. Gidrometeoizdat, St. Petersburg (in Russian)

Greze VN and 29 others (1984) The bioproductive system of the large-scale oceanic gyre (Bioproduktsionnaya sistema krupnomaschtabnogo okeanicheskogo krygovorota). Naukova Dumka, Kiev(in Russian)

Herbland A, Le Borgne R, Le Bouteiller A, Voituriez B (1983) Structure hydrologique et production primaire dans l'Atlantique tropical oriental. Océanogr Trop 18:249-293

IOC (1992) IOC Committee on International Oceanographic Data and Information Exchange. Proc 14th Session, 1-9 December 1992. UNESCO, Paris

Kiefer DA, Ondercin D (1993) Mapping and modeling of bioluminescence in the north Atlantic and Pacific oceans. In: Abstracts, Bioluminescence Symposium. Westin Maui Kaanapali Beach, Hawaii. November 5-10, 1993, p 82

Koblentz-Mishke OI (1977) Primary production. In: Vinogradov ME (ed) Biology of the ocean (Biologiya okeana), Vol 1. Nauka, Moscow, p 62-65 (in Russian)

Kondratieva TM, Markova LS (1975) The productive-physiological studies of the planktonic communities of the south Atlantic and the Mediterranean Sea. In: Greze VN (ed) Expeditional research in the south Atlantic and the Mediterranean Sea (Ekspeditsionnye issledovaniya $v$ Yjnoi Atlantike i Sredizemnom more). Naukova Dumka, Kiev, p 149-159 (in Russian)

Lapota D, Losee JR (1984) Observations of bioluminescence in marine plankton from the sea of Cortez. J Exp Mar Biol Ecol 77:209-240

Lapota D, Paden S, Duckworth D, Rosenberg DE, Case JF (1994) Codstal and oceanic bioluminescence trends in the Southern California Bight using MOOREX bathyphotometers. In: Campbell AK, Kricka LJ, Stanley PE (eds) Bioluminescence and chemiluminescence. John Wiley \& Sons, Chichester, p 127-131

Levitus S (1982) Climatological atlas of the world ocean. Prof Pap 13, NOAA, Washington, DC

Levitus $S$ (1988) Ekman volume fluxes for the world ocean and individual ocean basins. J Phys Oceanogr 18:271-279

Longhurst A. (1993) Seasonal cooling and blooming in tropical oceans. Deep Sea Res 40:2145-2165

Longhurst A, Sathyendranath S, Platt T, Caverhill C (1995) An estimate of global primary production in the ocean from satellite radiometer data. J Plankton Res 17:1245-1271

Losee J, Richter K, Liberman S, Lapota D (1989) Bioluminescence: spatial statistics in the North Atlantic. Deep Sea Res 36:783-801

Marra J (1989) Marine bioluminescence and upper ocean physics: seasonal changes in the Northeast Atlantic. Oceanography $2: 36-38$

Marra J, Hartwig EO (1984) Biowatt: a study of bioluminescence and optical variability in the sea. EOS 65:732-733

Martinenko SV (1988) Oceanologic characteristic of the upper pelagia of the Atlantic Ocean tropical zone. In: Zyev GV (ed) Macroplankton and nekton of the tropical Atlantic

This article was submitted to the editor
(Makroplankton i nekton tropicheskoi Atlantiki). Naukova Dumka, Kiev, p 10-27 (in Russian)

Martinenko SV (1990) The hydrophysical characteristic of the eastern equatorial Atlantic. In: Zyev GV (ed) Productivity of the equatorial Atlantic (Produktivnost ekvatorialnoi Atlantiki). Naukova Dumka, Kiev, p 17-56 (in Russian)

McClain RC, Firestone J (1993) An investigation of Ekman upwelling in the North Atlantic. J Geophys Res 98: $12327-12339$

McGowan JA (1971) Oceanic biogeography of the Pacific. In: Funnel BM, Reidel WR (eds) The micropalaeontology of the oceans. Cambridge University Press, London, p 3-74

Ondercin D, Atkinson CA, Kiefer DA (1996) The distribution of bioluminescence and chlorophyll during the late summer in the north Atlantic: maps and a predictive model. $J$ Geophys Res 100:6575-6590

Oudot C, Morin P (1987) The distribution of nutrients in the equatorial Atlantic: relation to physical processes and phytoplankton biomass. Oceanol Acta 6:121-130

Piontkovski SA, Ignatyev SM (1992) Macroscale distribution of zooplankton biomass of the tropical Atlantic. Hydrobiol J 28:20-25

Plontkovski SA, Williams R (1995) Multiscale variability of tropical ocean zooplankton biomass. ICES J Mar Sci 52: $643-656$

Rudjakov YuA (1968) Bioluminescence potential and its relation to the concentration of luminescent plankton. Okeanologiya 8:888-894 (in Russian)

Rudjakov YuA, Tseitlin VB (in press) The annual mean mesozooplankton biomass distribution in the upper layer of the Pacific and Indian Oceans. Proceedings of International Conference on Pelagic Biogeography. UNESCO Tech Rep. Paris

Rudjakov YuA, Voronina NM (1967) Plankton and bioluminescence in the Red Sea and the Gulf of Aden. Okeanologiya 7:1076-1088 (in Russian)

Semina GI (1977) Phytoplankton. In: Vinogradov ME (ed) Biology of the ocean (Biologiya okeana), Vol 1. Nauka, Moscow, p 58-62 (in Russian)

Swift E, Biggley WH, Verity PG, Brown DT (1983) Zooplankton are major sources of epipelagic bioluminescence in the southern Sargasso Sea. Bull Mar Sci 33:855-863

Swift E, Lessard EJ, Biggley WH (1985) Organisms associated with stimulated epipelagic bioluminescence in the Sargasso Sea and the Gulf Stream. J Plankton Res 7:831-848

Van der Spoel S, Heyman RP (1985) A comparative atlas of zooplankton, biological patterns in the oceans. Bunge. Utrecht

Vasilenko VI, Bitukov BG, Sokolov BG, Tokarev YuN (1997) Hydrophysical device 'SALPA' of the Institute of Biology of the Southern Seas used for bioluminescent investigation of the upper layers of the ocean. In: Hastings JW, Kricka LJ, Stanley PE (eds) Bioluminescence and chemiluminescence. Molecular reporting with photons. John Wiley \& Sons, Chichester, p 549-552

Manuscript received: February 28, 1997

Revised version accepted: August 8, 1997 